\title{
Assessment of Ankle Joint Proprioception in Cricket Players
}

\author{
Dhruti Mawani $^{1}$, Mayuri Ghumatkar ${ }^{2}$, Ajay Kumar ${ }^{3}$ \\ ${ }^{1}$ Student (BPT) DPO's Nett College of Physiotherapy, Thane \\ ${ }^{2}$ Associate Professor, DPO's Nett College of Physiotherapy, Thane \\ ${ }^{3}$ Principal, DPO's Nett College of Physiotherapy, Thane
}

Corresponding Author: Dhruti Mawani

\begin{abstract}
Background and Aims: Superior balance ability is necessary to achieve the highest competitive level and avoid lower limb injuries. Balance control improvement is one of the most important goals in sports and exercise. Better the balance, better is the performance. Proprioception plays an important role in balance control and ankle proprioception is arguably the most important. Cricket is an evolving sport and it the ankle-foot complex in the only part that comes in contact with the ground which further leads to ankle injuries. Ankle proprioception is altered by sport related injuries or fatigue all of which subsequently leads to altered balance mobility. Ankle injuries often lead to disruption of muscles and tendons with associated damage to inherent mechanoreceptors which detrimentally alters the quality of proprioceptive information required for balance control. This study consists of an assessment of ankle joint proprioception in cricket players using an active to active reproduction test.

Methodology: An observational study was conducted among 40 cricket players. Ankle proprioception was assessed using an active to active reproduction test. The mean differences between both the positions were then calculated.

Results: The result of this study showed a clinically significant difference in both ankle plantarflexion and ankle dorsiflexion. The results also showed that right sided movements were affected in subjects who are right sided dominant and the same was there for left sided dominant subjects. The mean errors in Right PF and Left PF was $4.15^{\circ}$ and $1.75^{\circ}$ respectively which signifies that Right $\mathrm{PF}$ is affected in cricket players. The mean errors in Right DF and Left DF were $2.825^{\circ}$ and $2.025^{\circ}$ respectively which signifies that Right DF is more affected than that of Left DF.

Conclusion: The ankle proprioception was affected in majority of the individuals. A clinically significant increase is noted in Right PF, Right DF and Left DF. Right plantarflexion was affected more than that of left plantarflexion and right dorsiflexion was affected more than that of left dorsiflexion. Hence, right sided dominant people showed affection in right sided movements and those who were left sided dominant showed affection in left sided movements. These results thus signify that the players are at mild risk of having ankle injuries because ankle proprioception is associated with ankle injuries which then indirectly affects the performance of the player.
\end{abstract}

Keywords: Ankle proprioception, Cricket Players, Balance, Active to Active reproduction test.

\section{INTRODUCTION} of sport."

"Cricket-A magic word in the sphere

Cricket is basically a bat and ball game played between two teams of eleven players. It is one of the oldest sports in the world and has its origin in $16^{\text {th }}$ Century in
England. Today cricket seems to be a virtual lifeline of many commonwealth nations. Cricket is one of the most internationally played sports. It is played by more than 120 million players in many countries which makes it the world's second most popular sport. 
The nature of this game is evolving and is associated with a low to moderate risk injury where cricket is showing a dramatic increase in injury incidence. (1) Despite of its popularity all over the world, not much research has been done on the subject of medicine in cricket. ${ }^{(2)}$

Orchard et al defined cricket injury as "any injury or other medical condition that either: (a) prevents a player from being fully available for selection for a major match or (b) during a major match, causes a player to be unable to bat, bowl or keep wicket when required by either the rules or the team's captain." (2)

Despite being the most popular sport in world, there have been relatively few publications in the medical literature on cricket injuries and fewer still that have been focused on foot and ankle injuries. ${ }^{(2)}$ Lower limb accounts for about $49.8 \%$ of injuries, out of which $10.6 \%$ injuries were that of ankle joint. ${ }^{(3,4)}$

Cricket involves batting, bowling and fielding and every aspect of this sport is subjected to cause injury. So, fewer studies have been done that shows higher incidence of injuries in bowlers. Studies showed that bowling accounted for about $50.7 \%$ of injuries. $(1,5)$

\section{BALANCE AND PROPRIOCEPTION}

In many sports, superior balance ability is necessary to achieve the highest competitive level and avoid lower limb injuries. Balance control improvement is one of the most important goals in sports and exercise. Better the balance, better is the performance. Proprioception plays an important role in balance control and ankle proprioception is arguably the most important.

Proprioception has been defined as one's ability to integrate the sensory signals from various mechanoreceptors to thereby determine body position and movements in space and it plays a crucial role in balance control.

Both balance and proprioception are negatively associated with ankle injuries. Ankle injuries often lead to disruption of muscles and tendons with associated damage to inherent mechanoreceptors which detrimentally alters the quality of proprioceptive information required for balance control. ${ }^{(6)}$

According to few studies conducted ankle joint is prone to injury during sports.

The most common type of ankle injury is ankle sprain and studies have shown that ankle proprioception is altered when there is an injury to the ankle.

As the proprioception gets affected, the performance of the player during sports gets affected.

Studies have been conducted on the assessment of proprioception of ankle in basketball players, soccer players, taekwondo practitioners and dancers. But very few studies have been conducted on the assessment of ankle joint proprioception in cricketers.

Hence this study is an attempt to assess the ankle joint proprioception in Cricket Players.

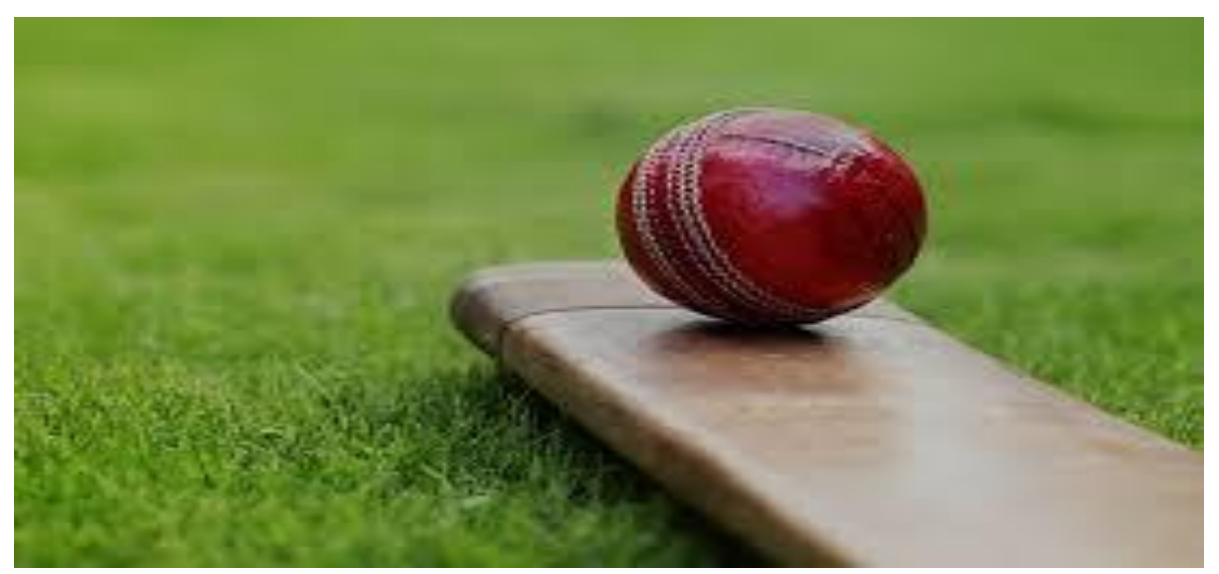




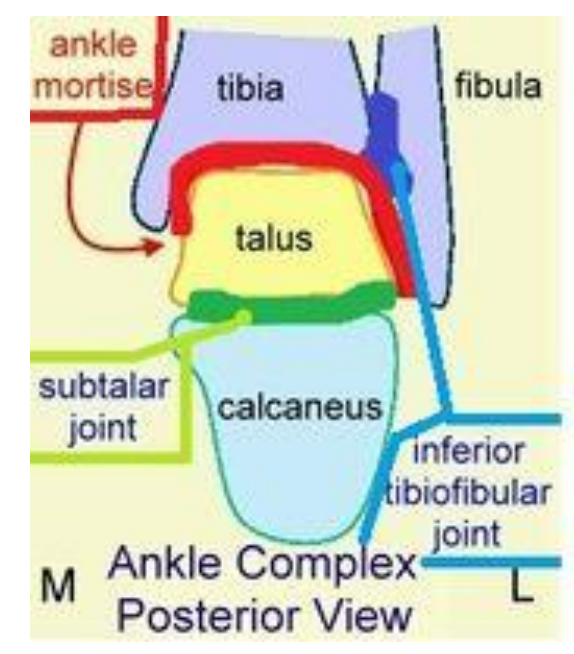

\section{MATERIALS AND METHODOLOGY MATERIAL}

Universal half goniometer. Paper.

Pen.

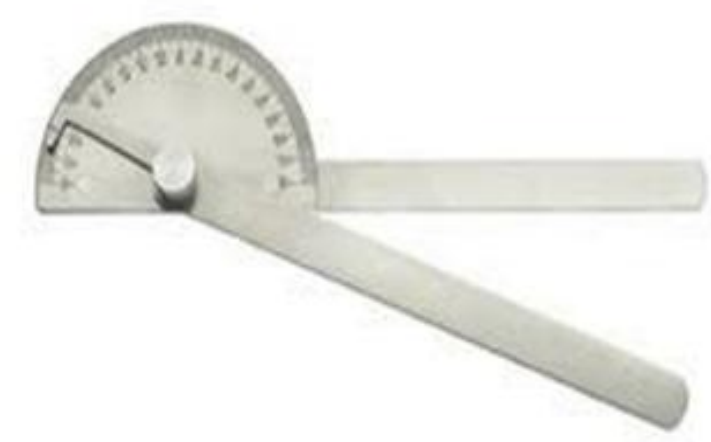

\section{$>$ STUDY DESIGN}

Type of study: Cross-sectional observational study

Duration of study: One year

Place of study: Sports club within metropolitan city

\section{$>$ SAMPLE DESIGN}

Sample size: 40

Sample population: Cricket players

Sampling: Convenient sampling.

\section{- INCLUSION CRITERIA:}

1. Cricket players willing to participate.

2. Age Group: between 18 to 45 years.

3. Players with an experience of 2 or more years.

- EXCLUSION CRITERIA:

1. Any recent ankle joint trauma or surgery.

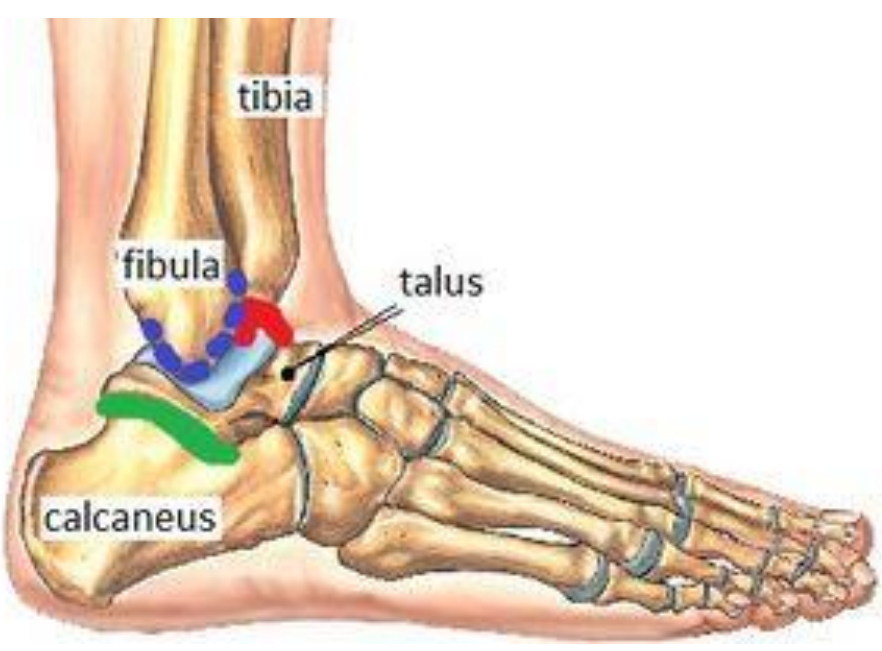

2. Any recent trauma to lower limb.

Ethical clearance from ethical committee of institution was taken. Permission consent from the manager of the club was taken. All Covid-19 related precautions were taken and screening was done for the same. A written informed consent was taken from the subject in the language best understood by them. Selection of the subjects was done based on the inclusion and exclusion criteria. The aim, need of study and procedure was explained to the subjects. Following which Active to Active reproduction test $(\mathrm{r}=0.83)$ for testing the ankle joint proprioception was done.

TECHNIQUE: Active to Active Reproduction test: Subject was taken in a long sitting position with knee extended. With eyes close, the therapist asked the patient to do the test movement actively and then I stopped the subject at a range of his/her choice. The angle was measured using a Universal half goniometer and the subject was then asked to concentrate on that position for 3 seconds. After which the ankle was brought to neutral position and with the eyes closed the subject was asked to reproduce the same joint position actively. The angle was again measured using a Universal half Goniometer. The absolute error was then measured by calculating the difference. (Difference of \pm 2 is considered normal) 
The data collected was then analysed and presented in the form of graphs.

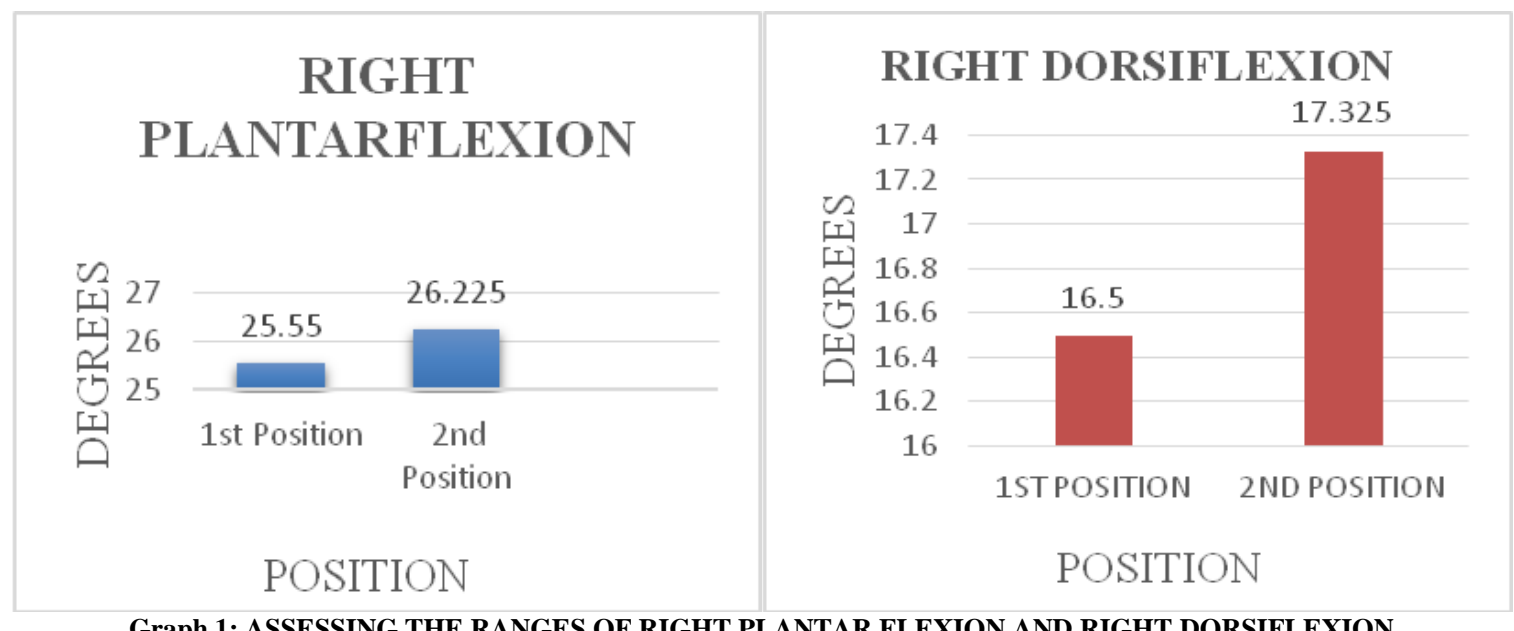

Graph 1: ASSESSING THE RANGES OF RIGHT PLANTAR FLEXION AND RIGHT DORSIFLEXION
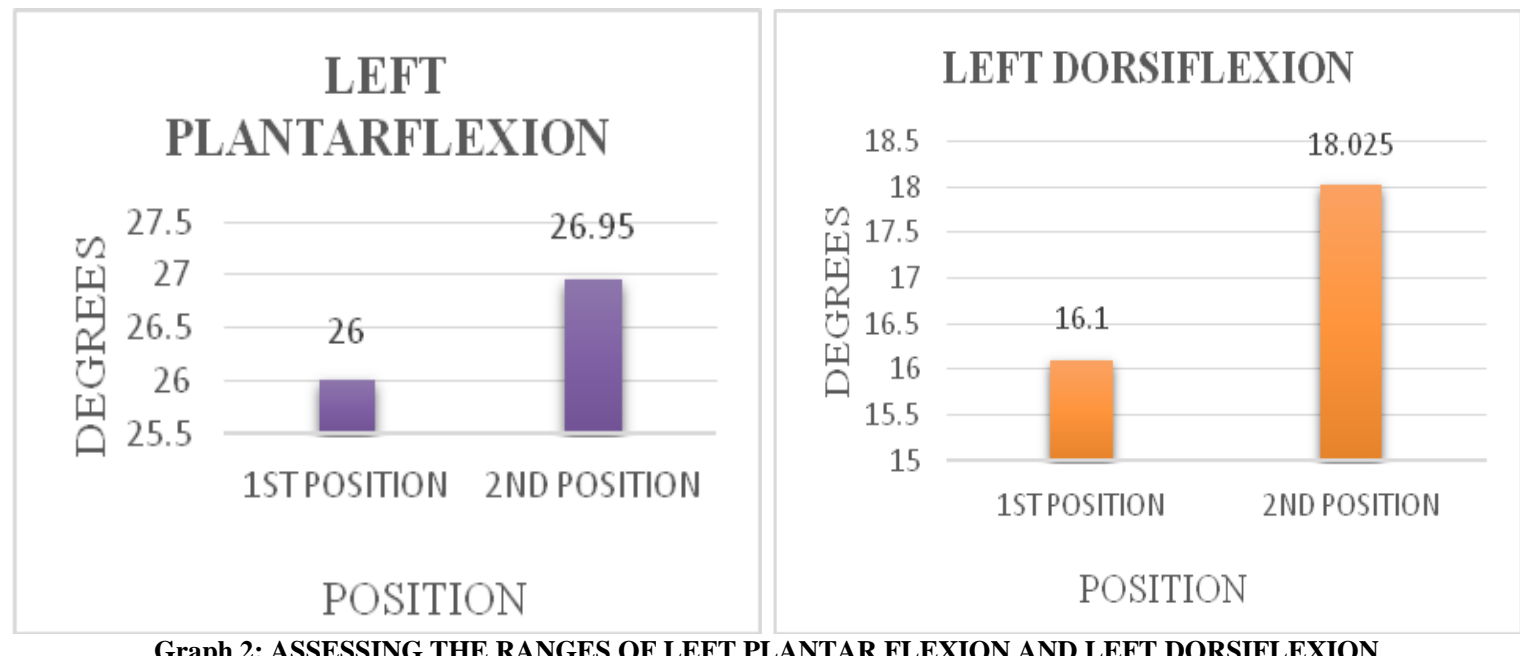

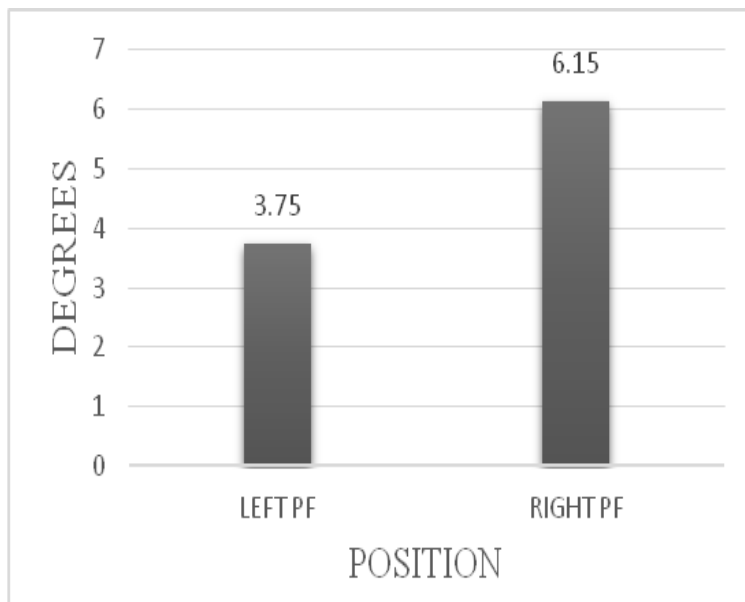

Graph 3: ASSESSING THE DIFFERENCE BETWEEN BOTH THE POSITIONS OF RIGHT PLANTAR FLEXION AND LEFT PLANTARFLEXION

INFERENCE: Ankle proprioception of Right plantarflexion is affected in 18 to 45 years of age group. Right PF > Left PF.
(Mean difference of \pm 2.0 is considered to be normal and so left PF is not affected)

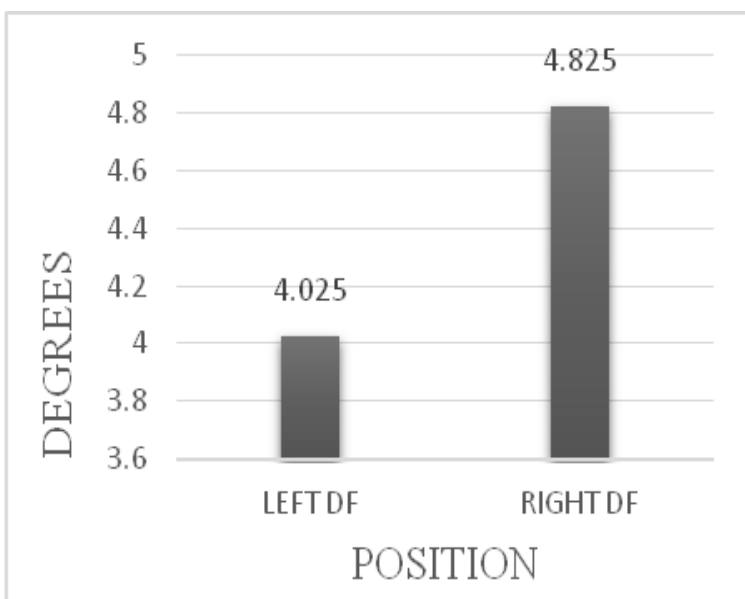

Graph 4: ASSESSING THE DIFFERENCE BETWEEN BOTH THE POSITIONS OF RIGHT DORSIFLEXION AND LEFT DORSIFLEXION 
INFERENCE: Ankle proprioception of Right dorsiflexion and Left dorsiflexion is affected in 18 to 45 years of age group. Right DF> Left DF.

\section{DISCUSSION}

Ankle proprioception is one of the most important components contributing to balance control in cricket because during most sports activities, the ankle-foot complex is the only part of the body that comes in contact with the ground. Ankle proprioception provides essential information to enable adjustments of ankle positions and movements of the upper body in order to successfully perform the complex motor tasks required in elite sport. Ankle proprioception is altered by sport related injuries or fatigue all of which subsequently leads to altered balance mobility. Ankle injures often leads to disruption of muscles and tendons with associated damage to inherent mechanoreceptors which detrimentally alters the quality of proprioceptive information required for balance control. ${ }^{(6)}$ Hence, the study is done to assess ankle proprioception in cricketers between the age group of 18-45 years according to the selection criteria. For the assessing the ankle proprioception Active to Active reproduction test is used in 40 individuals.

The data was analysed using descriptive statistics. The result of this study showed a clinically significant difference in both ankle plantarflexion and ankle dorsiflexion. The results also showed that right sided movements were affected in subjects who are right sided dominant and the same was there for left sided dominant subjects. The mean errors in Right PF and Left PF was $4.15^{\circ}$ and $1.75^{\circ}$ respectively which signifies that Right PF is affected in cricket players. The mean errors in Right $\mathrm{DF}$ and Left DF was $2.825^{\circ}$ and $2.025^{\circ}$ respectively which signifies that Right DF is more affected than that of Left DF.

Amy S. N. Fu, Christina W. Y. HuiChan stated a significant increase in ankle repositioning errors in basketball players with bilateral ankle sprains $(\mathrm{P}<.05)$. The mean errors in the right and left ankles were increased from $1.0^{\circ}$ and $0.8^{\circ}$ respectively, in the healthy players to $1.4^{\circ}$ and $1.1^{\circ}$ in the injured group. A significant increase in the amount of postural sway in the injured subjects was also found in conditions 1, 2, and 5 of the Sensory Organization Test $(\mathrm{P}<$ both ankles and postural sway angles in conditions 1, 2, and 3 of the Sensory Organization Test $(\mathrm{r}=0.39-0.54, \mathrm{P}<.05)$. (9)

Raweewan Lekskulchai and Supannikar Kadli stated that Passive JPS could indicate function of mechanoreceptors without motor effects. Greater errors in passive reproduction of children TKD practitioners with history of ankle sprains may indicate impairments of functions of mechanoreceptors. Ankle joint receptors may deteriorate due to previous ankle sprains. ${ }^{(10)}$

Subjects who showed clinically significant difference are more likely to have balance problems and thus are more prone to have ankle injuries during cricket. Poor proprioception is associated with poor play, ankle injuries and sprains and impaired balance.

Such factors therefore need to be addressed by health care workers and therapists managing with cricket players.

\section{LIMITATIONS}

- Small sample size

- Lack of training due to the pandemic.

\section{SUGGESTIONS}

- Similar study can be carried out on a broad scale with larger sample size to get a clearer picture.

- Similar study can be carried out with comparison between two groups.

\section{CONCLUSION}

The ankle proprioception was affected in majority of the individuals. A clinically significant increase is noted in Right PF, Right DF and Left DF. Right 
plantarflexion was affected more than that of left plantarflexion and right dorsiflexion was affected more than that of left dorsiflexion. Hence, right sided dominant people showed affection in right sided movements and those who were left sided dominant showed affection in left sided movements. These results thus signify that the players are at mild risk of having ankle injuries because ankle proprioception is associated with ankle injuries which then indirectly affects the performance of the player.

\section{Acknowledgement: None}

\section{Conflict of Interest: None}

\section{Source of Funding: None}

\section{Ethical Approval: Approved}

\section{REFERENCES}

1. Natashia. M. Milsom, Justhinus. G. Barnard, Richard.A.Stretch. Seasonal incidence and nature of cricket injuries among elite South African schoolboy cricketers. SAJSM. 2007, 19(3): 80-84.

2. Prof. Mandeep S. Dhillon, Dr. Sharad Prabhakar, Himmat Dhillion, Dr. Vikas Bachhal. Foot and ankle injuries in cricket: A review. J of Foot and Ankle Surgery. 2011, XXVI (2): 8-13.

3. R.A.Stretch. Cricket injuries: a longitudinal study of the nature of injuries to South African cricketers. Br J Sports Med. 2003, 37: 250-253.

4. Tim Leary, John A White. Acute injury incidence in professional country club cricket players 91985-1995. Br J Sports Med. 2000, 34: 145-147.

5. Dinshaw N. Pardiwala, Nandan N. Rao, Ankit V. Varshney. Injuries in Cricket. Sports health. 2018, 10(3): 217-222.

6. Jia Han, Judith Anson, Gordon Waddington, Roger Adams and Yu Liu. The Role of Ankle Proprioception for Balance Control in relation to Sports Performance and Injury. Biomed Research International. 2015: 1-8.
7. Nandini Deshpande; Reliability and Sensitivity of Ankle Proprioceptive Measures. School of Rehabilitation therapy. 2001: 1-111.

8. Daniel Tik-Pui Fong, Youlian Hong, Lap-Ki Chan, Patrick Shu-Hang Yung and KaiMing Chan. A Systematic Review on Ankle Injury and Ankle Sprain in Sports. Sports Medicine. 2007, 37(1): 73-94.

9. Amy S. N. Fu, Christina W. Y. Hui-Chan. Ankle Joint Proprioception and Postural Control in Basketball Players with bilateral Ankle sprains. The American Journal of Sports Medicine. 2005, 33(8): 1174-1182.

10. Raweewan Lekskulchai and Supannikar Kadli. Evaluation of Ankle Joint Position Sense in Children Taekwondo Practitioners with Ankle Sprain. Journal of Physiotherapy Research. 2017, 1(1:5): 1-5.

11. M H Noorbhai, F M Essack, S N Thwala, T $\mathrm{J}$ Ellapen, $\mathrm{J} \mathrm{H}$ van Heerden. Prevalence of cricket-related musculoskeletal pain among adolescent cricketers in KwaZulu-Natal. SAJSM. 2012, 24(1): 3-9.

12. Evert Verhagen, Allard van der Beek, Jos Twisk, Lex Bouter, Roald Bahr, Willem van Mechelen. The effect of a proprioceptive balance board training program for the prevention of ankle sprains. Sports Med. 2004, 32(6): 1385-1393.

13. Kyungmo han, Mark D. Ricard, Gilbert W. Fellingham. The effects of a 4-week exercise program on balance using elastic tubing as a perturbation force for individuals with a history of ankle sprains. Journal of orthopaedic and sports physical therapy. 2009, 39(4): 246-255.

14. Carrie L. Docherty, Josef H. Moore, Brent L. Arnold. Effects of Strength Training on Strength Development and Joint Position Sense in Functionally Unstable Ankles. Journal of Athletic Training. 1998, 33(4): 310-314.

How to cite this article: Mawani D, Ghumatkar M, Kumar A. Assessment of ankle joint proprioception in cricket players. Int $J$ Health Sci Res. 2021; 11(10): 196-201. DOI: https:// doi.org/10.52403/ijhsr.20211025 